\title{
REVIEW
}

\section{THE MILITARY FAMILY: DYNAMICS, STRENGTHS AND CHALLENGES}

Family relationships remain one of the most valuable and meaningful human experiences, within and outside of the military, and when loss or conflict occurs, this has profound effects on individuals and society. Furthermore, family support can influence occupational outcomes such as recruitment, retention, a nd military readiness. Family loyalty to the armed services can be transmitted intergenerationally and can influence public support for the military a s an institution. The interplay between the family, the military, and broader society are considered throughout this special issue.

This special edition on military families in Contemporary Military Challenges provides informative sociological perspectives on "military families" both in Slovenia and internationally. Each article tackles unique and significant issues related to military families and society. The lens of the socio-ecological model for risk and protective factor research, in combination with an implementation science approach and attention to contextual factors, is what is needed to move forward in supporting military families. Taken together, the articles in this special issue highlight the complexity and importance of military families and the related policy implications.

In the field of family science, not enough attention has been given to the implementation of science research. To do this, one needs to consider both current and past policies and how they have affected families at different socio-ecological levels. As a basis for considering policies and research agendas, the historical context of the family and its relationship with the military in Slovenia and internationally is a good start (see article by Jelusic, Jeznic, \& Juvan 2020). Research on military families in Slovenian Armed Forces is a relatively young field and of increasing importance given the changes in the last three decades, especially after becoming an all-voluntary force and the professionalization of the military. The authors detail the organizational and policy 
changes in Slovenia that have developed concurrently with military family research internationally and at home. The relevance of military families is now more widely recognized, yet barriers to the successful implementation of support programmes remain. The articles by Hess 2020, Jakopic 2020, and Kasearu et al. 2020 provide several examples of support programmes that can strengthen military families and bolster military family readiness. To achieve the best outcomes, the focus needs to not only be on the treatment of problems, but also on the primary prevention of risk factors and promotion of resilient families (e.g. through fostering high-quality intimate relationships). Promoting resilient families requires the provision of support at multiple levels of operation including psychological support, social care, legal counselling, and spiritual care.

In addition to contextual perspectives and policy review, another fundamental part of military family research is identifying the risk and protective factors for socioecological outcomes through empirical research. Vuga 2020 provides an action plan for current research to identify factors at different socio-ecological levels that affect family behavioural health outcomes. The risk and protective factors which are most associated with outcomes in the Slovenian military context can be targeted in future programmes and policies. This public health based approach has been applied in other countries to inform military leaders about the needs of their armed forces. In our own work with the US military, we employed risk and protective factor models to identify unique modifiable factors in predicting behavioural and family health outcomes, which could be targeted in interventions at the individual, family, professional and community levels. Vuga and her colleagues' expansion of the socio-ecological research model will be useful for the Slovenian Armed Forces and the results could be informative for other military organizations. Intervention derived from the risk and protective factor model from the MilFam project can then be tested in subsequent studies to ensure effective implementation and change in behavioural health outcomes. The MilFam project will serve as an important step in addressing the needs of military families in Slovenia.

Several other relevant considerations for military sociological research are raised in the other articles, including cross-country differences, deployment challenges, and demographic changes impacting the concept of "military families". The article by Kasearu et al. (2020) compares the concept of military families across three different countries. Whether families are seen as part of the military or separate, as is the case for some other professions, depends on how military service is defined in different countries. In some contexts, emphasis has been placed on policies for service members, and civilian family members are not considered. Although similar policies are common in many professions, there are certainly reasons unique to the military that suggest inclusive policies and programmes for civilian family members not only benefit military families but can also improve military preparedness. In the case of deployment, when policies are in place that do not support the significant other/spouse and children left behind it can lead to psychological distress, financial burdens, and impairment of family functioning. In the digital age, deployed service 
members are often well-informed about the problems at home and may become frustrated by the lack of policies in place to support military family members while they are deployed.

Besides the challenges faced by separations, military families also face unique challenges related to being stationed abroad with their families. The importance of the infrastructure and network to provide informal and formal support for family members as they navigate a new environment is critical in these situations. This includes both tangible and emotional support for family members as they adjust to living in a foreign country. Housing, medical care, schooling, language, and job options for family members are some of the concerns facing families while abroad. Depending on the size of the military infrastructure abroad, these concerns may be supported internally through the military. However, in many cases, sufficient internal support infrastructures may not be available and agreements with host countries can fill some of these gaps.

An added complexity is raised in the article by Švab (as well as in Jelušič et al. and Kasearu et al.), in that challenges facing military families not only depends on the military infrastructure and policies, but also on the family structure and dynamics. Jelušič et al. point out how the typical family of service members has evolved over time. Švab describes the dynamics of family structure across Slovenia and their interplay with military organizational needs. Family structure has changed significantly over the past few decades and this poses new challenges for military families. The changing family structures introduce diverse risks factors and areas to target with support programmes. The division of labour and family roles continues to evolve in Slovenia and internationally. There is a growing body of research that documents the relevance of gender and work division in the military context. Support for women service members with children varies from that of their male counterparts, and may require more targeted support programmes. In meeting the needs of diverse military family practices, attention to both formal and informal support networks in research and policy is necessary.

Throughout this special issue, specific examples of programmes already offered to support military families are mentioned. It is important, however, that programmes are not just implemented, but that effective programmes are implemented with a sound base of empirical support for their implementation. One example of this is the PREP programme (Preparation and Relationship Enhancement/Education Programme), which is offered in several countries to support intimate partnerships among military couples. This programme has evidence to support its effectiveness in reducing relationship distress over time across numerous studies.

This special issue makes it clear how important the military family is to effective professional functioning. Despite the clear importance of military families, they are often not supported sufficiently in various ways (e.g. through policies or evidencebased prevention offers). This not only influences professional outcomes such as 
job satisfaction, retention, days of missed work, and satisfaction with leadership, it also places families at risk of hardship and psychological distress. This in turn can cycle back into worse professional outcomes. Divorce/separations and living alone (i.e. social isolation) are associated with risks of depression and suicide, along with negative professional outcomes. Support programmes need to address changes in family structure that may be particularly stressful, as well as negative stressors that arise within family structures (e.g. family conflict and violence), which also, in turn, impact professional outcomes. This special issue draws attention to this cycle and will serve as a useful reference to generate further research studies and policies that will benefit the military and its families. 